\title{
Who is Taking our Classes? A Single-Institution Study of Leadership Student Personality Types
}

\author{
Nathaniel G. Pearson \\ Assistant Professor \\ Cabrini University \\ Lisa DeFrank-Cole \\ Associate Professor \\ West Virginia University
}

\begin{abstract}
Students register for leadership classes with a number of assumptions about leaders and their traits. These assumptions both explicitly and implicitly affect students' self-selection for leadership studies courses. This study compared the personality types of first-year leadership students at a Research 1 public university to the Myers-Briggs Type Indicator (MBTI) types of the general population. In several introductory leadership courses, students were given access to a free, shortened version of the MBTI entitled the Jung Typology Test. The data showed highly significant differences between the sample group and the general population in relation to their four-letter typologies. A discussion of these differences, specifically in the ways that we talk about leadership and recruit students to our programs, is presented.
\end{abstract}

\section{Introduction}

Leadership is a popular and often confusing buzzword, selling books, podcasts, and seminars in airport bookstores and corporate boardrooms across the globe. Clever marketing has built a leadership industry that amasses millions of dollars every year. The appeal of leadership seems nearly universal, and higher education institutions are capitalizing on this allure of leadership through online and brick-and-mortar programs and course offerings (Kellerman, 2012). The International Leadership Association (ILA) website (2016) lists over 2,000 leadership certificate, undergraduate, and graduate degree programs worldwide in a variety of formats. The draw of leadership as a psychological, self-help, and academic pursuit continues to intrigue students and professionals alike.

For most, the word, "leader," carries with it a positive connotation, describing a state for which many strive but seldom reach. In an informal survey of students on the first day of introductory leadership courses, leaders were described as being comfortable speaking in public, outgoing, well dressed, and persuasive. Asked to identify leaders, students' selections lean more toward celebrities and often-infamous historical figures than people who have been personally influential in their lives. This phenomenon, in which perceived leaders are revered beyond the scope of their reach or accomplishments, has been labeled the "romance of leadership" (Meindl \& Ehrlich, 1987, p. 91). In romanticizing leadership, the very concept of leadership is seen as the highest of callings, encompassing all things charismatic, powerful, and admirable. In its pervasiveness, the romanticization of leadership has served to cloud people's understanding of a 
leader's defining qualities. The authors well summarized this phenomenon by stating: "Leadership appears to have been sanctified" (p. 92).

A good starting point for any serious discussion of leadership, then, must start with a mutually agreed upon understanding of how the term is being defined. Northouse (2016) defined leadership as "a process whereby an individual influences a group of individuals to achieve a common goal" (p. 6). While one of a plethora of leadership definitions, His words provide a picture of leadership rife with depth and accessibility. This definition allows for leadership to extend beyond the highest rankings of celebrity to those who are impactful in people's daily lives. Northouse's definition of leadership applies to both presidents and to mothers; to CEOs and to little league coaches.

Students engage in an introductory course on leadership for a number of reasons. Many hope to learn more about leadership with hopes of developing their own skillsets and influence. Likewise, leadership programs appeal to students who have been placed in both formal and informal leadership situations during their curricular, social, and extracurricular careers. Students' self-identification as leaders underscores their interest in taking leadership classes, specifically when these classes are perceived to add value to the pupils' existing coursework. Haber (2012) summarizes students' leadership development in this way:

Research on students' leadership identity development suggests that over time students' understandings of leadership became more complex and relational, moving from hierarchical to more collaborative (Komives et al., 2005), while Schertzer and Schuh's (2004) study identified that students holding formal leadership roles tended to have more traditional and trait-focused understandings of leadership than the students who did not hold formal leadership roles. (p. 27)

Considering the aforementioned research, it is not surprising that students in introductory leadership courses focused on the traits of leaders. Based on our observations of students and their assumptions about leadership, we were curious about the range of personality types represented in leadership courses. Administering the Jung Typology Test, based on the categories of the MBTI, provided an opportunity to find out more about our students that could help us gauge the reach of our program.

\section{Purpose}

The purpose of this study was to compare the personality types of students, as categorized by the Jung Typology Test, to the Myers-Briggs Type Indicator (MBTI) types of the general population. The researchers were interested in knowing whether or not leadership studies students tend to cluster in one or few MBTI types. We hoped that this data would provide insights into students' explicit and implicit assumptions about leadership traits. Understanding the range of types represented by leadership students could help us ascertain the program's crosscampus reach and help us broaden recruitment efforts. 


\section{The Myers-Briggs Type Indicator}

The Myers-Briggs Type Indicator (MBTI) was originally developed in 1943 by Katharine Cook Briggs and Isabel Briggs Myers (Dunning, 2003). Built upon the type-theory of psychiatrist Carl Jung (1972), the test has been used by millions of people to better understand themselves and the people around them. The MBTI has long been used for organizational and leadership development (Gardner \& Martinko, 1996) and is the most widely used and studied psychological test today (Offerman \& Spiros, 2001). Approximately 2 million people take the MBTI annually (Aranda \& Tilton, 2013). According to CPP, the instrument's publisher, 89 of Fortune 100 companies utilize the MBTI for individual and team training (Myers-Briggs Type Indicator Instrument (MBTI) Personality Test, n.d.). Corporate use of the Myers-Briggs makes up at least $40 \%$ of the instrument's utilization (Gardner \& Martinko, 1996). Beyond the corporate sphere, the MBTI is well suited to academic and other learning applications (Rushton, Morgan, and Richard, 2007; Kent and Fischer, 1997). Michael (2003) underscored the inventory's ease of administration and interpretation as a core reason for its popularity andreach.

The MBTI (as well as the Jung Typology Test) yields 16 distinct types, which are fourletter combinations that describe a person's personality based on four dichotomies: Extraversion vs. Introversion; Sensing vs. iNtuition; Thinking vs. Feeling; Judgment vs. Perceiving. These dichotomies, or preferences, are used to describe the manner in which people perceive (sensing/intuition) and judge (thinking/feeling) external stimuli, as well as the ways in which they build energy (extraversion/introversion) and interact with the outside world (judging/perceiving) (Gardner \& Martinko, 1996). The dichotomies are further described in Figure 1, which is based upon the descriptions crafted by Mattare (2015) and the descriptions on myersbriggs.org (2016).

The Jung Typology Test is an online personality test that is made up of 64 distinct ipsative items (as compared with the 93 items found in the MBTI). Participants choose from five possible responses for each statement. Once all items have been completed, the students are given a four-letter type that corresponds to those used on the Myers-Briggs Type Indicator. The results page gives the respondent both their four-letter type and a brief description of that type, as well as the percentages of preference for each of the four dichotomous categories. 
Extraversion vs. Introversion ( $E$ vs. I) This dichotomy indicates how a person gets his or her energy. Extraverts (E) are energized by other people and social situations, while an introvert (I) needs time to recharge alone to find energy from within.

Sensing vs. Intuition ( $S v s . N$ ) Sensing and intuition describe the ways in which people perceive information. $S$ types tend toward those things that are concrete and can be perceived with the senses. $\mathrm{N}$ types tend to focus on possibilities, symbols, and patterns. Thinking vs. Feeling ( $T$ vs. F) These types have to do with the ways that people make decisions. Thinking $(\mathrm{T})$ is associated with the analytical while the Feeling $(\mathrm{F})$ preference is associated with subjective and people-focused issues.

Judging vs. Perceiving ( $J$ vs. $P$ ) Judging and perceiving describe how people interact with the outside world. The judging type prefers a more structured lifestyle, while the perceiving type thrives on flexibility and adaptation.

Figure 1

MBTI dichotomies and descriptions

It is worth noting that there is some debate regarding the scholarly merits of the MBTI. McCrae \& Costa (1989) criticized many of the test's psychometric properties. They, and others, highlighted the limitations of the Myers-Briggs in terms of its theoretical basis, ipsative format (Schriesheim, Hinkin, \& Podsakoff, 1991), and distribution limitations (Furnham, 1995). Mattare (2015) drew attention to a high degree of skepticism in research circles surrounding the MBTI due to the inventory's “overuse and/or misuse" (p. 114).

Many of the critiques of the Myers-Briggs Type Indicator compare the inventory with the NEO-PI five-factor model of personality, commonly referred to as the Big Five. While the MBTI is often used in business and team-oriented settings, the Big Five is heavily utilized in academic literature. Criticism of the MBTI generally relates to the test's shortcomings as a standalone measure. One oft-discussed limitation of the Myers-Briggs is in the ipsative nature of the items, which force participants to choose among limited options (Schriesheim, Hinkin, \& Podsakoff, 1991). Tests takers are then placed into one of the 16 possible types, which do not take into account the degree to which a person falls within a particular preference. For example, a person who is $3 \%$ extravert is still categorized together with the $99 \%$ extravert, with no distinguishing factors within their type. Another limitation of the MBTI is in the inventory's inherent bias towards positivity (Mattare, 2015). Every type description is focused around the strengths of that particular combination of preferences, with little stated about specific deficits of the participant's personality.

Even though academics often have strong preference for the NEO-PI over the MBTI, research has shown consistent overlap between the two measures (Furnham, 1995; McCrae \& Costa, 1989). In fact, there are many signs of promise in the use of the MBTI in a specific capacity due to the test's accessibility and ease of interpretation. When used for applications such as team building, education, and personal exploration/improvement, the Myers-Briggs Type Indicator can be a helpful and easily accessible tool. A number of past and recent studies have declared the MBTI to be both valid and reliable for research purposes (Mattare, 2015; Honaker, 2003; Carlson, 1985). 


\section{The Study and its Methods}

Using a postpositivist epistemological paradigm and a non-experimental quantitative approach, researchers collected anonymous student data across several introductory courses on leadership over a one-and-a-half-year period. Due mainly to its simplicity and accessibility, a modified version of the Myers-Briggs Type Indicator was deemed the ideal instrument for the purposes of an introductory course on leadership. A link to the free personality assessment (Humanmetrics.com), entitled the Jung Typology Test, was provided to students as part of their coursework. The Jung Typology Test, like the MBTI, produces sixteen four-letter types that are based on the personality theory of Carl Jung.

Students from six sections of an introductory class on leadership ( $\mathrm{N}=218)$ were asked to complete the Jung Typology Test in nine classes across three semesters from 2015-2016. The participants were enrolled in leadership studies courses at a Big XII, Research 1 institution located in the Mid-Atlantic region. The results were collected and categorized by gender with all identifying information removed.

\section{Findings and Analysis}

Of those completing the survey, $79.27 \%$ of the participants were found to be extraverts (see Table 1). This percentage far exceeds that of the general population of extraverts, which Dunning (2003) measured at 49.4\%. This significant variation could be attributed to a number of factors. It is of little surprise that extraverts are attracted to the subject of leadership studies. As previously discussed, the construct of leadership has long been associated with the trait of extraversion, both socially and psychologically (McCrae \& Costa, 1989). Additionally, this finding aligns with previous research. Using the NEO-PI, Judge, Bono, Ilies, \& Gerhardt (2002) found a significant correlation between leadership and extraversion, more so than with any of the other four factors of personality. 


\begin{tabular}{lrrrrrr}
\hline \multicolumn{6}{l}{ Table l } \\
Numbers and Percentages of Student Respondents Across Type \\
\hline Type & \# of Females & \# of Males & TOTALS & \%Female & $\%$ Male & $\%$ TOTAL \\
ENFJ & 13 & 14 & 27 & $\mathbf{1 6 . 6 7 \%}$ & $\mathbf{1 0 . 0 0 \%}$ & $\mathbf{1 2 . 3 9 \%}$ \\
ENFP & 5 & 23 & 28 & $6.41 \%$ & $\mathbf{1 6 . 4 3 \%}$ & $\mathbf{1 2 . 8 4 \%}$ \\
ENTJ & 7 & 31 & 38 & $8.97 \%$ & $\mathbf{2 2 . 1 4 \%}$ & $\mathbf{1 7 . 4 3 \%}$ \\
ENTP & 1 & 12 & 13 & $1.28 \%$ & $8.57 \%$ & $5.96 \%$ \\
ESFJ & 16 & 11 & 27 & $\mathbf{2 0 . 5 1 \%}$ & $7.86 \%$ & $\mathbf{1 2 . 3 9 \%}$ \\
ESFP & 6 & 5 & 11 & $7.69 \%$ & $3.57 \%$ & $5.05 \%$ \\
ESTJ & 7 & 12 & 19 & $8.97 \%$ & $8.57 \%$ & $8.72 \%$ \\
ESTP & 4 & 3 & 7 & $5.13 \%$ & $2.14 \%$ & $3.21 \%$ \\
INFJ & 6 & 6 & 12 & $7.69 \%$ & $4.29 \%$ & $5.50 \%$ \\
INFP & 1 & 1 & 2 & $1.28 \%$ & $0.71 \%$ & $0.92 \%$ \\
INTJ & 5 & 13 & 18 & $6.41 \%$ & $9.29 \%$ & $8.26 \%$ \\
INTP & 1 & 1 & 2 & $1.28 \%$ & $0.71 \%$ & $0.92 \%$ \\
ISFJ & 0 & 2 & 2 & $0.00 \%$ & $1.43 \%$ & $0.92 \%$ \\
ISFP & 0 & 1 & 1 & $0.00 \%$ & $0.71 \%$ & $0.46 \%$ \\
ISTJ & 6 & 5 & 11 & $7.69 \%$ & $3.57 \%$ & $5.05 \%$ \\
ISTP & 6 & 0 & 0 & $0.00 \%$ & $0.00 \%$ & $0.00 \%$ \\
TOTAL & 140 & 218 & $100.00 \%$ & $100.00 \%$ & $100.00 \%$ \\
\hline
\end{tabular}

More specifically, the largest percentage of extraverted students fell into the ENTJ category $(17.43 \%)$, while the most frequent category for introverted students was INTJ $(8.26 \%)$. The frequency of these combinations in particular mirrors the findings of research in the realms of business and leadership. In their quantitative study of 408 managers and professionals, Brown \& Reilly (2009) noted a strong correlation between the MBTI categories of extraversion (E) and intuition $(\mathrm{N})$ with transformational leadership. This finding replicated that of Hautala (2006), who found a similar correlation between self-reported transformational leadership and the Eand $\mathrm{N}$ categories of the MBTI. Aranda and Tilton (2013) observed that $85.3 \%$ of executives showed a combined preference for both thinking (T) and judging (J). According to Dunning (2003), a mere $1.8 \%$ of the general population scores as ENTJ. By contrast, the most frequent type distribution across the general population, at $13.8 \%$, is that of ISFJ, a type marked by 
compassion, loyalty, and a tendency to go with the established flow (Dunning, 2003). In this sample, however, only $0.92 \%$ of participants reported the ISFJ combination.

The Chi-Square $\left(\chi^{2}\right)$ value was found to be

$$
\chi^{2}(15, \mathrm{n}=218)=728.91, p<.001, \varphi=.47
$$

This marks a notable difference in the distribution of MBTI types across the sample when compared to the general population. A $p$-value of less than .001, as well as a substantial effectsize $(\varphi=.47)$, underscores the significance of this difference. The results underscore the researchers' assumptions that enrollment in the institution's introductory leadership courses fails to mirror the MBTI typology of the general population. While some clusters of student personalities are well represented, appearing with greater frequency than within the population, other types are far underrepresented within the sample.

\section{Table 2}

Distribution of Respondent MBTI Types Compared with U.S.Population

\begin{tabular}{ccccc}
\hline MBTI Type & Sample \% & U.S. Population \% & Difference \\
\hline ENFJ & 12.39 & 2.5 & 9.89 \\
ENFP & 12.84 & 8.1 & 4.74 \\
ENTJ & $\mathbf{1 7 . 4 3}$ & 1.8 & $\mathbf{1 5 . 6 3}$ \\
ENTP & 5.96 & 3.2 & 2.76 \\
ESFJ & 12.39 & 12.3 & .09 \\
ESFP & 5.05 & 8.5 & -3.45 \\
ESTJ & 8.72 & 8.7 & .02 \\
ESTP & 3.21 & 4.3 & -1.09 \\
INFJ & 5.5 & 1.5 & 4.0 \\
INFP & .92 & 4.4 & -3.48 \\
INTJ & $\mathbf{8 . 2 6}$ & 2.1 & $\mathbf{6 . 1 6}$ \\
INTP & .92 & 3.3 & -3.48 \\
ISFJ & .92 & $\mathbf{1 3 . 8}$ & $\mathbf{- 1 2 . 8 8}$ \\
ISFP & .46 & 8.8 & $\mathbf{- 8 . 3 4}$ \\
ISTJ & 5.05 & 11.6 & -6.55 \\
ISTP & 0.0 & 5.4 & -5.4 \\
\hline
\end{tabular}

It should be noted that the number of male participants $(n=140)$ nearly doubled that of females $(n=78)$. This disparity mirrors enrollment in our introductory courses on leadership. Remarkably, the overall institutional enrollment is nearly a 50/50 split between males and females. In addition to the notable difference in course enrollment by sex, the MBTI typology 
differed across gender lines as well. The differences in male and female types may provide some insights into efforts to expand the program's reach across the student population. As mentioned, the most frequently appearing type, by far, was ENTJ, with $17.43 \%$ of the course population reporting this type. Of the $17.43 \%$ of students scored as ENTJ, 81.6\% were male. Female participants scored most frequently as INFJ or ISTJ (7.69\% each), types that were only reported by approximately $4 \%$ of the male participants.

\section{Limitations}

A key limitation of this study was in the actual instrument used. While the online assessment, the Jung Typology Test, is based on the ideas of the MBTI and yields the same typologies, it is both shorter than and different from the Myers-Briggs Type Indicator. We recognize that while the results may provide some interesting information regarding tendencies within the group, the inferences that can be made in regards to MBTI type must be limited accordingly. These qualifications were carefully considered in choosing to use the shortened version of the test for this study. It was decided that the ease of access, time savings, and costbenefits of the free test outweighed the advantages of utilizing the full version of the MyersBriggs Type Indicator for this application.

\section{Conclusions and Recommendations}

Through self-selection, students enrolling in leadership studies courses at a Big XII, R1 institution display a notable predisposition toward executive thinking types. While this is to be expected in business and management courses, it presents a challenge to the multidisciplinary approach in leadership studies. It could be argued that students who would most benefit from gaining additional skills and knowledge covered in leadership classes such as initiative-taking, situational leadership, and group dynamics are missing out on such learning based on preconceived ideas about leadership.

It seems worth considering, then, the assumptions that people hold about leadership and what it takes to be a leader. Could those who are attracted to an elective course on leadership be those individuals that have already been selected for both formal and informal leadership positions based on their extraverted nature? Might people who are extraverted self-select for leadership courses based upon their own presuppositions about leadership? These questions should be developed further in future research through various methods with varying populations.

Based on the findings herein, the researchers posit that the leadership archetypes outlined in trait-based approaches to leadership (Zaccaro, 2007) continue to flourish. Though the Trait Approach is one of the oldest theories explaining leadership, it appears that its appeal has not diminished. Conscious and unconscious assumptions about leaders' personalities and traits seem to pervade student experiences and expectations. Although introverts make up over $50 \%$ of the population (Dunning, 2003), they are not finding their way into our leadership classrooms. According to Susan Cain (2013), the rise of the culture of personality in the early $20^{\text {th }}$ century led to the societal association of extraverts with leadership. With Carnegie's (1936) classic text How 
to Win Friends and Influence People, a new way of thinking emerged. The rise in the number of people living in cities, rather than rural areas, made crucial the ability to network and use one's personality to sell oneself to others. Extraversion became an admired and often necessary trait. Cain (2013) remarked:

We see talkers as leaders. The more a person talks, the more other group members direct their attention to him, which means that he becomes increasingly powerful as a meeting goes on...all of this would seem fine if more talking were correlated with greaterinsight, but research suggests that there's no such link (p. 51).

In order to more fully explore the best practices of leadership, the academic discipline of leadership needs to be intentional about drawing students from a variety of backgrounds and personality types. By encouraging more introverts to take our courses, all students may have a better opportunity to learn from different personality types. Programs like ours may want to expand their recruiting of students to disciplines such as the hard sciences and the creative artsplaces from which we draw a very limited number of students. While recruiting efforts may have minimal initial impact, a few students who develop a passion for leadership will go a long way in spreading the word about the accessibility and applicability of leadership across a number of fields. As we have come to know about teams, those with the most diversity are apt to produce the best results (Higgs, 2005). We believe the same to be true of leadership.

\section{References}

Aranda, R., \& Tilton, S. (2013). Myers-Briggs personality preferences may enhance physician leadership success in non-clinical jobs. Physician Executive, 39, 14-20.

Brown, F. W., \& Reilly, M. D. (2009). The Myers-Briggs Type Indicator and transformational leadership. Journal of Management Development, 28, 916-932.

Cain, S. (2013). Quiet: The power of introverts in a world that can't stop talking. New York: Random House.

Dunning, D. (2003). Introduction to type and communication. Palo Alto, CA: CPP, Inc.

Furnham, A. (1995). The big five versus the big four: The relationship between the MyersBriggs Type Indicator (MBTI) and NEO-PI five factor model of personality. Personality and Individual Differences, 21, 303-307.

Gardner, W. L., \& Martinko, M. J. (1996). Using the Myers-Briggs Type Indicator to study managers: A literature review and research agenda. Journal of Management, 22, 45-83.

Haber, P. (2012). Perceptions of leadership: An examination of college students' understandings of the concept of leadership. Journal of Leadership Education, 11(2), 26-51. 
Higgs, M., Ulrich, P., \& Ploch, J. (2005). Influence of team composition and task complexity on team performance. Team Performance Management: An International Journal. 11(7/8): $227-250$.

Judge, T.A., Bono, J.E., Ilies, R., \& Gerhardt, M.W. (2002). Personality and leadership: A qualitative and quantitative review. Journal of Applied Psychology, 87, 765-780.

Jung, C. G. (1972). Two essays on analytical psychology ( $2^{\text {nd }}$ ed.). (G. Adler \& R.F.C.Hull, Trans.). Princeton, NJ: Princeton University Press.

Jung Typology Test (2016). Retrieved from http://www.humanmetrics.com/cgi-win/jtypes1.htm.

Kellerman, B. (2012). The end of leadership. New York, NY: HarperCollins.

Kent, H. \& Fischer, D. (1997). Associations between teacher personality and classroom environment. Presented at the Annual Meetings of the American Educational Research Association, Chicago, IL.

Mattare, M. (2015). Revisiting understanding entrepreneurs using the Myers-Briggs Type Indicator. Journal of Marketing Development and Competiveness, 9, 114-119.

McCrae, R. R., \& Costa, P. T. (1989). Reinterpreting the Myers-Briggs Type Indicator from the perspective of the Five-Factor model of personality. Journal of Personality, 57, 17-40.

Meindl, J. R. \& Ehrlich, S. B. (1987). The romance of leadership and the evaluation of organizational performance. Academy of Management Journal, 30, 91-109.

Michael, J. (2003). Using the Myers-Briggs Type Indicator as a tool for leadership development? Apply with caution. Journal of Leadership and Organizational Studies, 10, 68-81.

Myers, S. (2016). The five functions of psychological type. The Journal of Analytic Psychology, 61, 183-202.

Myers-Briggs Type Indicator Instrument (MBTI) Personality Test. (n.d.). Retrieved September 23, 2016, from https://www.cpp.com/products/mbti/index.aspx

Northouse, P.G. (2016). Leadership: Theory and practice ( $7^{\text {th }}$ ed.). Thousand Oaks, CA: Sage Publications, Inc.

Offerman , L. R., \& Spiros, R. K. (2001). The science and practice of team development: Improving the link. Academy of Management Journal, 44, 376-392.

Rushton, S., Morgan, J., \& Richard, M. (2007). Teachers' Myers-Briggs personality profiles: Identifying effective teacher personality traits. Teaching and Teacher Education, 23, 432441. 
Schriesheim, C., Hinkin, T., \& Podsakoff, P. (1991). Can ipsative and single-item measures produce erroneous results in field studies of French \& Raven's (1959) Five Bases of Power? Journal of Applied Psychology, 76, 106-114.

Stulp, G., Buunk, A. P., Verhulst, S., \& Pollet, T. V. (2013). Tall claims? Sense and nonsense about the importance of height of US presidents. The Leadership Quarterly, 24, 159-171.

Tzeng, O. C. S., Outcalt, D., Boyer, S. L., Ware, R., \& Landis, D. (1984). Item validity of the Myers-Briggs Type Indicator. Journal of Personality Assessment, 48, 255-256.

van Engen, M. L., van der Leeden, R. \& Willemsen, T. M. (2001). Gender, context and leadership styles: A field study. Journal of Occupational and Organizational Psychology, 74, 581-598.

Zaccaro, S. J. (2007). Trait-based perspectives of leadership. American Psychologist, 62, 6-16.

\section{Author Biographies}

Nathaniel Pearson, Ph.D. is Assistant Professor and Program Coordinator of the Leadership Studies Program at Cabrini University. His research and practice interests include classroom and workplace engagement, meaning, and servant-leadership. nathaniel.pearson@cabrini.edu

Dr. Lisa DeFrank-Cole is Associate Professor and Director of Leadership Studies at West Virginia University (WVU). She served as the 2015 chair of the Women and Leadership Affinity Group in the International Leadership Association. Her primary research interest is in the combined topics of women and leadership. Lisa.DeFrank-Cole@ mail.wvu.edu. 